\title{
Putnam, Kuhn e A Relatividade conceitual
}

\author{
ROBINSON GUITARRARI
}

\begin{abstract}
The understanding of conceptual relativity in Putnam's and Kuhn's writings should not be restricted to the claim that the existence is relative to, but not in virtue of, a conceptual scheme. This approach does not capture some significant differences between their positions about the notion of conceptual scheme. We understand that the thesis of conceptual relativity contains a statement about the close relationship between conceptual scheme and content, and another claim about the differences between conceptual schemes. Based on these two formal requirements, we propose a reconstruction of the Putnam's treatment of it and show how it can be understood from Kuhn's perspective of scientific development. We defend that, although both fulfill a critical role against metaphysical realism, they are applied to distinct domains: while Putnam's conceptual relativity is in the record of the conceptual structure of scientific theories and presupposes a choice between cognitively equivalent conceptual schemes, Kuhn considers the field of the dynamics of development of science. Thus, we note relevant scientific cases of conceptual relativity that do not involve semantic incommensurability.
\end{abstract}

Keywords: Conceptual relativity; incommensurability; relativism; Putnam; Kuhn.

\section{O problema}

Intuitivamente, a mensagem que o emblema "relatividade conceitual" carrega supõe a distinção entre esquema conceitual e conteúdo e, de certo modo, um tipo de relatividade que objetos, propriedades, relações e categorias de entidades mantêm com esquemas conceituais. Porém, trata-se de uma tese que não afirma simplesmente que a linguagem é fator primordial para o acesso a itens extralinguísticos, pois isso pode ocorrer com a existência de uma única linguagem. Dizer, então, que conteúdo é relativo a esquema conceitual implica a existência de esquemas conceituais que, sob algum aspecto relevante, não se sobrepõem.

Nessa medida, a relatividade conceitual se contrapõe à concepção que afirma a existência de um mundo independente, tanto da linguagem como da mente, e também rivaliza com a ideia de que há uma única linguagem capaz de descrever corretamente os objetos (e propriedades) desse mundo em si. Essas são duas teses centrais do realismo metafísico não humano, ${ }^{1}$ tal como o caracterizou Putnam quando promoveu o realismo interno (1981, p.49). Desde Meaning and moral science (1978), ele usou a relatividade conceitual como uma das razões para rejeitar ambas as afirmações do realismo metafísico.

Principia 20(2): 285-314 (2016).

Published by NEL — Epistemology and Logic Research Group, Federal University of Santa Catarina (UFSC), Brazil. 
Em Reason, truth and history (1981), Putnam afirmou que a resposta à questão acerca de quais objetos existem no mundo não poderia ser dada sem recurso a um esquema conceitual. Destacou que essa relatividade conceitual, embora se oponha ao realismo metafísico, não envolve forma alguma de relativismo cognitivo. Ele disse: "Negar que faça sentido perguntar se nossos conceitos "se relacionam" com algo absolutamente não contaminado de conceitualização é uma coisa; sustentar que todo sistema conceitual é, por isso, tão bom quanto qualquer outro é algo diferente" (1981, p.54). Particularmente, a relatividade conceitual, assumida para responder à questão acerca de quais são os objetos existentes no mundo, não deveria estar associada a um relativismo cognitivo presente na proposta de Kuhn. Putnam tratou disso mais detidamente (1981, pp.113-24).

Ainda que Kuhn não tenha um trabalho sistemático sobre a relação entre os domínios semântico e ontológico, há indicações que poderiam, de fato, preocupar Putnam.

Kuhn notou, com base em uma analogia com a psicologia da percepção, que o produto de um ato perceptivo não é estabelecido exclusivamente por aspectos do objeto de percepção: categorias ou parâmetros conceituais cumprem um papel singular, ainda que não exclusivo, na determinação de como o objeto da percepção é identificado e com o que ele é identificado. Ora, a impregnação conceitual da percepção, presente nessa abordagem, envolve a distinção entre esquema conceitual e conteúdo. Essa é uma tese que Putnam aceita. Mas, quando Kuhn declara que certas diferenças entre esquemas conceituais são caracterizadas por uma incomensurabilidade semântica, passando a defender que léxicos ou linguagens científicas incomensuráveis dão acesso a diferentes mundos possíveis (Kuhn 1990, p.300), a divergência entre ambos se põe. Essa é uma tese que Putnam não aceita.

O ponto de Putnam é relevante. Levando em conta que seu realismo interno buscava uma via média entre o relativismo cognitivo e o realismo metafísico, a rejeição do relativismo kuhniano tornava-se central. Nesse contexto, ele entendeu que, ao defender a relatividade conceitual, seria necessário frisar que, com essa tese, não viria junto o relativismo cognitivo, uma perspectiva que ele às vezes associou ao slogan "vale tudo", como também à formulação "todo esquema conceitual é tão bom quanto qualquer outro".

De fato, o realismo interno agrega um conjunto de teses que não cede espaço ao relativismo cognitivo. Sua concepção de verdade como idealização da aceitabilidade racional cumpre esse papel. Sendo transcultural, normativa e fortemente epistêmica, ela foi colocada como alternativa entre a noção correspondencial de verdade, comumente associada ao realismo metafísico, e uma relativização das noções de verdade e de racionalidade. Mas para o propósito de apresentar o problema a ser tratado, pretendo destacar outro aspecto que também distancia Putnam do relativismo cognitivo: a relatividade conceitual.

Principia 20(2): 285-314 (2016). 
Sosa procurou esclarecer a posição de Putnam com respeito à relatividade conceitual quando disse que "a existência relativa a um esquema conceitual não é equivalente à existência em virtude de um esquema conceitual" (1993, p.621). Mas essa tentativa de dar inteligibilidade à mencionada tese não distingue as posições de Putnam e de Kuhn, pois ambos não defendem que o mundo é construído pelos léxicos. Ambos se contrapõem a versões do construtivismo social caracterizado pela dependência forte do que se considera como mundo em relação ao esquema conceitual adotado.

Mais recentemente, Boyd entendeu que a posição de Putnam captura "a ideia de que questões sobre a realidade ou existência das coisas, espécies, magnitudes etc. têm determinadas respostas somente relativas a uma escolha de linguagem, jogo de linguagem, esquema conceitual, paradigma de pesquisa ou coisas que tais" (2013, pp.45-6). Ainda que concedamos como mero deslize relativizar as mencionadas questões ontológicas à escolha de esquemas conceituais, em vez de considerar os esquemas conceituais, nota-se que a formulação de Boyd sequer distingue Putnam de um construtivista, quanto menos de Kuhn. ${ }^{2}$

De fato, Sosa ressaltou apenas uma das características da tese em jogo: a relação entre esquema conceitual e conteúdo. Porém, para tratar das diferenças entre Putnam e Kuhn, é necessário cuidar de outro aspecto da mesma tese: as diferenças entre esquemas conceituais.

Putnam é um crítico severo da incomensurabilidade semântica, entendida por Kuhn como intraduzibilidade entre partes de esquemas conceituais. No entanto, desde sua fase como realista interno, Putnam passou a aceitar a relatividade conceitual, destacando que esquemas conceituais rivais podem, de certo modo, ser traduzidos, e seu conhecido exemplo da "soma mereológica" expôs a relatividade conceitual como uma questão de convenção. Por outro lado, ele também defendeu que "dois enunciados incompatíveis at face value podem algumas vezes ser verdadeiros (e a incompatibilidade não pode ser explicada afirmando que cada um dos enunciados possui "um significado distinto" dentro dos esquemas a que respectivamente pertence)" (Putnam 1990, p.x). Se Putnam está certo ao dizer que as traduções não preservam a ontologia, podemos entender que essa mudança de ontologia se deva apenas ao uso de diferentes convenções? O que, para ele, seria preservado, em uma tradução, havendo uma mudança na ontologia? Das divergências entre ambos a respeito da traduzibilidade entre esquemas conceituais rivais, decorreriam diferentes implicações ontológicas? Que compreensão cada um possui da relatividade conceitual e de suas implicações?

O presente artigo pretende tornar mais claras as posições de Putnam e de Kuhn com respeito à relatividade conceitual. Mais especificamente, indicaremos que a tese proposta por Putnam e aquela defendida por Kuhn são distintas e que essa diferença pode ser apresentada com base na compreensão que cada um possui sobre a noção de esquema conceitual e sobre suas disparidades. Além disso, mostraremos que suas for- 
mulações não são incompatíveis, embora Putnam não aceite a formulação de Kuhn, tendo em vista seu compromisso com o realismo.

Para tanto, assumiremos que a tese da relatividade conceitual possui dois componentes: um deles marca a ideia da relação entre esquema conceitual e conteúdo - algo que é, de certo modo, compartilhado por ambos; o outro procura estabelecer o tipo de relação que esquemas conceituais mantêm entre si, suas semelhanças e diferenças. É, sobretudo, esse segundo aspecto que explicará as particularidades de cada formulação, suas funções e seus domínios de aplicação.

A tentativa de formular a tese da relatividade conceitual em Putnam e em Kuhn deve, dentre as exigências a serem satisfeitas, contemplar seu papel no interior do quadro filosófico que cada um propõe. Tendo em vista essas reconstruções, vale ressaltar que, no caso de Kuhn, o segundo aspecto da relatividade conceitual, que trata das diferenças e semelhanças entre esquemas conceituais, associa-se à incomensurabilidade semântica, uma tese que ele sempre defendeu, ainda que com algumas alterações. Levaremos em conta, para os nossos propósitos, suas formulações mais maduras, apresentadas em artigos dos anos 80 e 90. No caso de Putnam, a relatividade conceitual foi defendida desde as primeiras formulações do realismo interno (1976-1989), abarcando o realismo natural, que começou a receber uma configuração mais articulada a partir de Dewey Lectures (1994a) até seus últimos escritos. ${ }^{3}$ À luz de críticas e de análises construtivas, Putnam procurou apenas esclarecer essa tese, sem a intenção de alterá-la. Por isso, serão analisados seus pronunciamentos dessas duas fases realistas.

Encaminhando dessa maneira nossa tarefa de esclarecer as diferenças entre as formulações de Putnam e de Kuhn, desenvolveremos uma reconstrução das duas condições formais que compõem, a nosso ver, a tese da relatividade conceitual especificando, portanto, a relação esquema conceitual/conteúdo e as diferenças entre esquemas conceituais. Com esse tratamento, será possível notar que o equívoco de Sosa, ao procurar caracterizar a posição de Putnam, foi o de enfatizar a primeira condição, sem mencionar a segunda, enquanto o de Boyd foi o de compreender erroneamente a caracterização da primeira condição.

$\mathrm{O}$ fato de a relatividade conceitual possuir esses dois aspectos formais joga luz à sua importância epistemológica: refutar a tese realista da convergência, segundo a qual há uma teoria verdadeira e completa para a qual as teorias maduras de uma mesma linhagem histórica se dirigiriam. ${ }^{4}$

A relevância de nossa análise, ao pretender distinguir especificamente esses dois tipos de relatividade conceitual, defendidos por Kuhn e por Putnam, é que, ao contrário do que em geral se supõe, a defesa de esquemas conceituais rivais (ou alternativos) nem sempre envolve formas de relativismo. ${ }^{5}$ Ambas as formulações contrapõem-se à perspectiva realista metafísica e não humana, caracterizada por defender, dentre outras teses, a existência de uma única linguagem correta e completa que captura 
o mundo, cuja existência é independente da mente e da linguagem. Mas, diferentemente de Kuhn, a de Putnam pode servir a uma postura não relativista em termos cognitivos. Isso se dá dessa maneira por conta da função que sua tese cumpre e do domínio de aplicação que ela possui. Com isso, notam-se casos de relatividade conceitual em que as divergências conceituais não são casos de incomensurabilidade semântica.

\section{Kuhn e a relatividade conceitual}

A compreensão da tese de Kuhn segundo a qual "[1]éxicos diferentes [...] dão acesso a conjuntos diferentes de mundos possíveis" (1990, p.300) supõe uma formulação da relatividade conceitual (embora ele não tenha usado essa expressão) à medida que se deve examinar tanto a relação entre esquema conceitual e conteúdo como uma diferença radical entre esquemas conceituais. ${ }^{6}$ Ambos os aspectos são controversos e exigem interpretação.

Preliminarmente, convém destacar que os trabalhos produzidos por Kuhn nos anos 80 e 90 serviriam, em grande medida, para a publicação de um livro ${ }^{7}$ que trataria da "incomensurabilidade em novas bases", como nos conta Hoyningen-Huene, mencionando conversas pessoais com Kuhn (Hoyningen-Huene 2015, p.190).

Os próprios textos de Kuhn indicam que, nessa nova fase, deixaram de ser tratadas, tal como haviam sido contempladas em The structure (1970a), a incomensurabilidade ontológica relacionada à percepção, e a incomensurabilidade epistemológica, que se vinculava à relação que tanto o cientista individual como a comunidade científica mantinham com o paradigma em contextos de disputa entre compromissos científicos rivais. O próprio termo "paradigma" passou a ser evitado, tendo em vista, segundo Kuhn, o fato de "ter perdido totalmente o controle" dos usos que fez dele (Kuhn 1991b, p.221).

Seguindo Hoyningen-Huene, que teve acesso a manuscritos de conferências relevantes para o desenvolvimento do mencionado livro, e levando em conta artigos desenvolvidos a partir dos anos 80 que se referem a esse projeto, o fio condutor do livro inacabado de Kuhn pode ser brevemente descrito do seguinte modo.

A história da ciência, de qualquer área, precisa de um ponto de partida. A reconstrução dessa fase inicial está na linguagem usada pelas fontes históricas relevantes do período. A linguagem científica possui uma estrutura lexical que exibe uma ordem entre termos para espécies, segundo a qual, para cada nível da hierarquia, os termos do léxico do mesmo nível satisfazem o princípio de não sobreposição. O que se denominava "ciência normal" em The structure agora se refere à fase de estabilidade da estrutura lexical da teoria em questão. Uma anomalia, problema recalcitrante que abalava o paradigma, está relacionada agora à violação desse princípio de sobrepo-

Principia 20(2): 285-314 (2016). 
sição ou de alguma relação hierárquica da estrutura lexical. Segundo HoyningenHuene, "os conjuntos de espécies estruturadas cumprem o papel que os paradigmas possuíam em Structure" (2015, p.193).

O resultado da reconstrução interpretada de uma ciência em fase inicial apresenta um feixe de conceitos inter-relacionados que difere do conjunto de conceitos contemporâneos do mesmo campo de estudo. De modo geral, a dinâmica do desenvolvimento da ciência apresenta períodos de estabilidade lexical intercalados por períodos de instabilidade. Embora ocorram alterações no período de estabilidade, elas são meras adaptações ou pequenos ajustes. Já as mudanças promovidas depois de um período de instabilidade são mais profundas. A diferença entre o antigo e o novo léxico é capturada pela noção de incomensurabilidade. Uma consequência dessa noção é que diferentes taxonomias lexicais (ou esquemas conceituais) capturam mundos distintos.

Dessa forma, a incomensurabilidade caracteriza a diferença entre esquemas conceituais (ou estruturas lexicais), enquanto sua implicação ontológica - a tese da diversidade de mundos - reforça a ideia de uma relação estreita entre esquema conceitual e conteúdo. Daí ambos os componentes da relatividade conceitual em Kuhn.

\subsection{Esquema conceitual e mundo}

Em The structure, Kuhn mencionara que a mudança de paradigma tinha um aspecto ontológico importante, ao afirmar que o cientista que muda de paradigma passa a viver em outro mundo. Isso não é apenas expresso por uma relação entre esquema conceitual e mundo, mas entre percepção e mundo, como indicam as seguintes passagens:

Uma mudança na rede de compromissos de uma disciplina altera a rede conceitual pela qual os cientistas veem o mundo (1970a, p.102);

Em períodos de revolução, quando a tradição científica normal muda, a percepção que o cientista possui de seu meio ambiente deve ser reeducada em algumas situações familiares, ele deve aprender a ver uma nova Gestalt. Depois disso, o mundo de sua pesquisa parecerá, aqui e ali, incomensurável com o que ele habitava anteriormente (1970a, p.112).

Um dos problemas para compreender a posição de Kuhn consiste em entender o que designa o termo "mundo" em usos como esses.

Hoyningen-Huene (1993) propôs uma interpretação "kantiana" para as revoluções científicas como mudanças de mundo. Segundo ele, devem ser considerados dois diferentes significados para o termo "mundo" nas passagens em que Kuhn enfatiza as implicações ontológicas dessas revoluções: o mundo dos fenômenos (ou dos objetos da experiência), do qual se pode ter conhecimento; e o mundo em si, que não pode ser conhecido. ${ }^{8}$

Principia 20(2): 285-314 (2016). 
De fato, artigos de Kuhn dão respaldo a essa interpretação. Em particular, as noções de estímulo e dados, destacadas em "Second thoughts on paradigms" (1974), cumprem um papel central. A ideia é que "membros de comunidades científicas diferentes são apresentados a dados diferentes pelos mesmos estímulos" (Kuhn 1974, p.309 n.18). Para Kuhn, o cientista não tem acesso aos estímulos, mas aos dados; analogamente, dentro da interpretação de Hoyningen-Huene, o cientista não tem acesso ao mundo em si, mas ao mundo dos fenômenos.

Entender que Kuhn usa "mundo" nos dois sentidos indicados dá inteligibilidade a passagens como "embora o mundo não mude com a mudança de paradigma, os cientistas depois disso operam em um mundo diferente" (Kuhn 1970a, p.121). Além disso, essa leitura também tem a virtude de apreender a ideia de que, para Kuhn, o mundo investigado pela ciência depende tanto da natureza como do esquema conceitual, de tal modo que ele não seria, em particular, um construtivista social, no sentido de que aquilo que se toma por "real" é tão somente o resultado do recorte dado pelos esquemas conceituais das melhores teorias.

Kuhn subscreveu a reconstrução (de sua primeira fase) proposta por HoyningenHuene (1993). Isso implicaria a aceitação dessa interpretação "kantiana" sobre os seus pronunciamentos com respeito à mudança de Gestalt.

Não obstante a plausibilidade da leitura de Hoyningen-Huene, Bird ofereceu outra interpretação. Para ele, os usos que Kuhn faz de "mundo" e "mudança de mundo" são metáforas comuns, como quando falamos "do mundo do poeta, do jogador de futebol etc., para nos referirmos ao seu meio social e aos tipos de atividades nos quais estão engajados". Sua proposta toma "o mundo do cientista como sua matriz disciplinar - a constelação de relações e compromissos profissionais, técnicas instrumentais e teóricas, e, sobretudo, os exemplares-chave da disciplina" - e leva em conta que essa matriz muda (Bird 2008, p.34).

Ainda que não haja consenso sobre como interpretar as passagens em que Kuhn menciona uma mudança de mundo, é preciso frisar que há acordo sobre o fato de que a ciência, de um ponto de vista kuhniano, não trata do suposto mundo em si. Além disso, não é negado um papel da natureza no desenvolvimento científico. Como Kuhn ressaltou em "The trouble with the historical philosophy of science" (1992), não é o caso de sugerir "que haja uma realidade não alcançada pela ciência" (1992, p.115). Para ele:

o que substitui o único e grande mundo independente da mente sobre o qual se dizia que os cientistas descobriam a verdade é a variedade de nichos nos quais os praticantes dessas várias especialidades praticam seu ofício. Esses nichos [...] são tão sólidos, reais e resistentes a mudanças arbitrárias quanto já se disse ser o mundo exterior. Todavia, ao contrário do chamado mundo exterior, não são independentes da mente e da cultura, e não se reduzem a um único todo coerente do qual nós e todos os praticantes de todas as especialidades científicas individuais somos habitantes (Kuhn 1992, p.120).

Principia 20(2): 285-314 (2016). 
Desse modo, critica-se a existência de um mundo independente de qualquer aparato cognitivo como objeto da investigação científica e, além disso, rejeita-se a ideia de que o mundo é construído exclusivamente por um léxico amplamente aceito - afinal, existe a contraparte do esquema conceitual, a saber, o nicho no qual os cientistas praticam seu ofício.

Essa relação que o esquema conceitual mantém com o mundo não é uma via de mão única. Deixar de lado a ideia de que Kuhn é um construtivista, no sentido posto, significa valorizar o papel que a natureza cumpre na relação que o cientista individual e a comunidade científica possuem com as teorias científicas e com os esquemas conceituais a elas associados. De acordo com o que Kuhn propôs, a realidade tratada pelos cientistas também possui alta relevância nas mudanças e nas resistências a mudanças de uma estrutura lexical. Caso contrário, conforme coloca Bird, como poderíamos conceber a possibilidade de realizar descobertas na atividade científica ordinária e entender a existência de anomalias na dinâmica da ciência? (Bird 2000, pp.123-4) O que Sosa afirmou para Putnam também vale para Kuhn: aquilo que é relativo ao esquema conceitual não existe meramente em virtude do esquema conceitual.

\subsection{Incomensurabilidade semântica e mundos concebíveis}

Kuhn se preocupou com uma explicação das experiências de historiadores da ciência com passagens sem sentido de célebres textos extemporâneos, como ocorre, por exemplo, com os usos do termo "movimento" na Física de Aristóteles e nas mecânicas de Galileu e de Newton, ou como no caso de "planeta" nas astronomias ptolomaica e copernicana (Kuhn 1981, pp.15-7). Em sua compreensão, essas experiências se assemelham a anomalias linguísticas detectadas por historiadores que procuram compreender tais passagens com um léxico diverso daquele que é usado na obra investigada (Kuhn 1990, p.299). Nesse contexto, a importância da relatividade conceitual, dentro de um quadro kuhniano de desenvolvimento da ciência, consiste em compreender tratamentos científicos que estejam distantes historicamente do léxico que dominamos, em vez de tratá-los como abordagens extravagantes. Nessas duas duplas de casos históricos, há léxicos distintos em jogo, com diferentes peculiaridades.

As diferenças mais profundas entre esquemas conceituais rivais, para Kuhn, resultam de revoluções científicas e são caracterizadas pela noção de incomensurabilidade em sua dimensão semântica. Assim, a compreensão da afirmação de que esquemas conceituais distintos descrevem conjuntos distintos de mundos possíveis depende da caracterização dessa noção. Para tanto, serão acentuados os seguintes aspectos: a intraduzibilidade entre léxicos (ou esquemas conceituais) rivais; o registro localizado da incomensurabilidade; a aprendizagem como meio de acesso ao léxico rival; e a consequente possibilidade de compreensão do léxico rival e de comparação entre seus méritos cognitivos.

Principia 20(2): 285-314 (2016). 
Dentro do debate em torno da incomensurabilidade semântica, ocorrido desde a publicação de The structure (1970a), em 1962, Kuhn apresentou várias formulações da tese: destacou-a como negação da existência de uma linguagem neutra a que se pudesse recorrer para realizar a tradução da linguagem de um paradigma para a linguagem de outro (1970a, p.201; 1970b, p.162), mas também a apresentou como a negação da possibilidade de tradução entre as linguagens envolvidas, sem fazer referência a uma linguagem neutra ${ }^{9}$ (1983, p.34).

Outra característica da incomensurabilidade semântica que, embora tenha sempre estado presente em Kuhn, recebeu tratamento mais detido nos artigos das décadas de 80 e 90 é seu aspecto parcial (não total). Em "Commensurability, comparability, communicability" (1983), afirma-se a existência de registros comensuráveis entre linguagens ditas incomensuráveis e declara-se que o problema de tradução está circunscrito a um pequeno grupo de termos e sentenças, de tal modo que a intraduzibilidade está localizada nas áreas em que duas taxonomias lexicais diferem entre si (Kuhn 1983, p.36).

Mais tarde, em "Dubbing and redubbing" (1990), sem usar "paradigma", Kuhn a enuncia em termos das linguagens vinculadas a "um par de teorias da mesma linhagem histórica". Diz ele: "não há uma linguagem comum em que as duas [teorias] poderiam ser inteiramente traduzidas" (1990, p.299). Disso decorre que "[a]lguns enunciados constitutivos da teoria mais antiga não poderiam ser afirmados em qualquer linguagem adequada para expressar sua sucessora e vice-versa" (1990, p.299). De fato, essa impossibilidade de tradução completa é a impossibilidade de realizar a "atividade quase mecânica inteiramente governada por um manual que especifica, em função do contexto, que sequência de palavras de uma linguagem pode, salva veritate, ser substituída por uma dada sequência da outra" (1990, p.299).

Seguindo a linha de tornar mais precisa sua tese da incomensurabilidade semântica, Kuhn, em "The road since Structure" (1991a), enfatiza que suas declarações de que as mudanças de significados de um termo se devem a mudanças de linguagem são muito abrangentes e que, em vez disso, é preciso restringir essa metáfora linguística a "termos taxonômicos ou termos para espécies", que constituem "uma categoria ampla que inclui espécies naturais, espécies artificiais, espécies sociais e provavelmente outras" (Kuhn 1991a, p.92). Em um léxico conceitualmente estruturado, tais termos satisfazem o princípio de não sobreposição (uma condição para rotular espécies) e relações hierárquicas. A incomensurabilidade entre estruturas lexicais não resulta, portanto, da falha de tradução de conceitos individuais, uma vez que um termo não aparece só em uma estrutura lexical. A incomensurabilidade ocorre porque não é possível traduzir os feixes problemáticos de termos sem violar o princípio de não sobreposição ou alguma relação hierárquica no interior da estrutura conceitual (Kuhn 1991a, p.93).

Sem a traduzibilidade plena, as partes comensuráveis, constituídas por termos 
que preservam seus significados na mudança de teoria, fornecem, segundo Kuhn, uma base para a compreensão das teorias rivais (Kuhn 1983, p.36). Ele chegou a afirmar que "qualquer coisa que pode ser dita em uma linguagem pode, com suficiente imaginação e esforço, ser compreendida por uma falante de outra linguagem" (Kuhn 1990, p.300).

Essa compreensão por meio da aprendizagem resulta de uma atividade que, diferentemente da tradução, não requer o conhecimento das linguagens que estão em jogo. Trata-se de um processo que, de modo geral, ocorre em contextos adequados de uso do novo esquema conceitual e que envolve, dentre outros aspectos importantes, a descrição e aplicação repetida de exemplos paradigmáticos (Kuhn 1993, p.225).

Na ciência, como os termos são projetáveis, o domínio de seu uso correto envolve generalizações sobre a natureza. Para distinguir melhores estratégias de aprendizagem, cabe levar em conta se o termo possui um conjunto de contraste - como "líquido" em relação a "sólido" e "gás" - ou se o termo em questão não possui uma classe contrastante, como é o caso de "força". Em ambas as situações, os termos devem ser aprendidos conjuntamente. Mas enquanto os que possuem classe de contraste são apresentados com seus respectivos referentes, aqueles que não a possuem são aprendidos com termos com os quais estão "estreitamente relacionados", usando exemplos de aplicações das leis em que comparecem (no caso de "força", que está diretamente relacionado aos termos "massa" e "peso", usam-se instâncias das leis de Newton e da lei de Hooke) (Kuhn 1993, pp.230-1).

Enfim, a aprendizagem de uma nova teoria não exige tradução completa e pode ser alcançada. Por meio dela, um esquema conceitual rival pode ser acessado e, consequentemente, a intraduzibilidade local, característica da incomensurabilidade entre partes de esquemas conceituais rivais, não impede em princípio a comunicação entre usuários de estruturas conceituais distintas nem a comparação dos méritos cognitivos e pragmáticos das teorias que elas expressam.

Para finalizar a apresentação dessa noção de incomensurabilidade, é importante destacar os limites que ela impõe a uma semântica de mundos possíveis e ao papel de uma teoria causal da referência.

Tomando o conceito informal de mundo possível, segundo o qual se trata de "um modo como nosso mundo poderia ter sido", Kuhn defende que a mudança de esquemas conceituais restringe os mundos possíveis a serem quantificados (Kuhn 1989, pp.63-4).

A leitura de Kuhn sobre os que discutem a lógica dos mundos possíveis é de que eles parecem assumir que tudo pode ser dito em qualquer linguagem. Contrariamente, Kuhn entende que:

[q]uestões sobre a semântica de enunciados modais ou sobre a intensão de palavras e sequências de palavras são ipso facto questões sobre enunciados

Principia 20(2): 285-314 (2016). 
e palavras em uma linguagem específica. Somente mundos possíveis estipuláveis nessa linguagem podem ser relevantes a elas (Kuhn 1989, p.64).

Ora, a incomensurabilidade semântica estabelece uma restrição importante para que não se cometam erros de querer encaixar a anomalia linguística da ciência extemporânea em sua linguagem atual: não se devem incluir mundos que sejam acessíveis apenas por meio de esquemas conceituais que são incomensuráveis com aquele utilizado pelo historiador da ciência (Kuhn 1989, p.64). ${ }^{10}$

Além disso, ressalta-se que uma teoria causal da referência não ajudaria nesse caso. Para Kuhn, um risco do historiador que supõe que tudo pode ser dito em qualquer linguagem é assumir, como procedem certas formas de realismo, que uma teoria da referência pode estabelecer a ponte entre teorias rivais de uma mesma linhagem histórica.

De acordo com essa teoria causal, a referência é uma relação entre entidades extralinguísticas que existem independentemente de nosso aparato cognitivo (as chamadas espécies naturais) e entidades linguísticas. Para um realista metafísico, existe uma totalidade fixa de objetos no mundo, disponíveis para descoberta e nomeação, e a relação de referência seria estabelecida de maneira puramente causal, quer dizer, sem atribuir papel relevante a intenções humanas ou a elementos descritivos. ${ }^{11}$

Como foi dito, Kuhn, ao afirmar que "[1]éxicos diferentes [...] dão acesso a conjuntos diferentes de mundos possíveis" (1990, p.300), assume a distinção entre esquema conceitual e conteúdo, admite a relatividade dos objetos no tocante aos conceitos e estabelece a diferença entre esses esquemas conceituais (ou léxicos) rivais como uma incomensurabilidade semântica, quer dizer, como impossibilidade de tradução completa entre as partes destoantes desses esquemas conceituais (ou léxicos). Léxicos são vocabulários estruturados. Mudanças no léxico podem alterar os significados de termos que nele se relacionam. Um novo léxico exibe outras relações entre alguns de seus termos como forma de dar conta das anomalias que apontam a violação do princípio de sobreposição ou um problema na hierarquia da estrutura lexical. Desse novo léxico surgem novas possibilidades de acessar o mundo de que se trata.

Com essa visão, Kuhn se opôs aos pronunciamentos de Putnam em "The meaning of "meaning"' (1975), distanciando-se de uma visão realista da teoria causal da referência. Kuhn notou dificuldades na concepção de que um ato original de batismo de um termo é um determinante da referência. A aplicação do termo "água" na Terra e na Terra Gêmea é um exemplo usado para destacar a diferença. Considerando o mundo possível em que há uma Terra Gêmea, planeta como o nosso exceto no que se refere ao termo "água" (enquanto aqui é $H_{2} 0$, lá é $X Y Z$ ), e levando em conta um único léxico, padronizado pela química moderna, Putnam nota que esse caso indicaria um erro na teoria química. Para Kuhn, a teoria causal em jogo não fornece uma 
ponte para casos históricos: $\mathrm{H}_{2} \mathrm{O}$, em 1750, era uma substância líquida; anos depois, passou a envolver as formas gasosa e sólida.

Diferentemente de uma perspectiva realista dessa teoria da referência, Kuhn defende que o batismo é um processo recorrente. Desse modo, "[o]s conjuntos de exemplos canônicos usados na transmissão do léxico mudam no curso do tempo, e nem todas as mudanças podem propriamente ser vistas como meros ajustes" (Kuhn 1990, p.314). Nem todos os ajustes são semelhantes a refinamentos de processos de purificação do ouro. Nesse caso, a eficácia do processo de purificação decorre de uma atividade de solução de problemas como se fossem quebra-cabeças, na qual o objetivo é encaixar a natureza dentro das expectativas decorrentes do uso bem-sucedido de um léxico estruturado. Porém, Kuhn tem em mente ajustes "sistemáticos e amplos", produtos de revoluções científicas caracterizados pela incomensurabilidade semântica. Dessa perspectiva, a designação rígida proposta por um realista metafísico para espécies naturais é vulnerável, inviabilizando uma conexão entre esquemas conceituais incomensuráveis.

Numa revolução científica, o mundo de experiência muda com a alteração sistemática e ampla de parte da estrutura lexical. Não obstante, esse mundo de que trata o esquema conceitual não é uma mera construção linguística, tendo em vista o papel que a natureza cumpre nos pequenos ajustes que os cientistas realizam nos períodos de estabilidade e nos grandes ajustes em períodos de instabilidade, ao longo do desenvolvimento de uma ciência.

\section{Putnam e a relatividade conceitual}

Putnam abandonou componentes essencialistas, com os quais sua concepção causal em "The meaning of "meaning"' (1975) estava associada, quando, em 1976, passou a defender seu realismo interno. Embora Kuhn reconheça esse aspecto e mencione a existência de "paralelos significativos" entre ambos, nenhum ponto foi destacado (Kuhn 1990, pp.317-18, n.23).

Em sua autobiografia intelectual, recentemente publicada, Putnam conta que "não pensou "The meaning of "meaning"” pressupondo alguma posição metafísica com respeito à questão sobre a natureza da relação entre representações linguísticas e a realidade" (2015a, p.82). Relata que abandonou a perspectiva externalista do realismo metafísico e passou a defender o que chamou, em Meaning and moral science (1978), de realismo interno, uma concepção que se tornou mais bem-acabada em Reason, truth and history (1981).

O internalismo de Putnam se pôs como uma via média realista entre o relativismo cognitivo e o realismo metafísico. De um lado, para ele, o relativismo cognitivo seria autodestrutivo, porque autorrefutante e porque lhe faltaria uma noção de correção

Principia 20(2): 285-314 (2016). 
objetiva para distinguir "estar certo" de "pensar que está certo". De outro, o realismo metafísico assume o ponto de vista do olho de Deus, por conta da perspectiva externalista que se lhe associa.

Em favor de um realismo com face humana, Putnam defendeu uma noção transcultural e epistêmica de verdade, além da tese da relatividade conceitual. ${ }^{12}$ Diferentemente do realista metafísico, ele propôs, em seu realismo interno, que aquilo que se considera objeto depende do esquema conceitual adotado (não havendo uma linguagem única para acessar a realidade); além disso, rivalizando com uma noção correspondencial, a verdade é entendida como o que é racionalmente aceitável em condições ideais. Desse modo, ela é antirrealista no sentido de que depende do aparato cognitivo humano (sendo assim, uma noção epistêmica), mas antirrelativista porque é transcultural — contrapondo à incomensurabilidade entre unidades epistêmicas rivais. ${ }^{13}$

Enquanto refratário ao realismo metafísico, Putnam, por outro lado, se aproximou de Kuhn. Dentre as teses compartilhadas, afirmam que não se pode falar do mundo sem referência a esquemas conceituais. Contudo, esse é apenas um componente da relatividade conceitual. É preciso notar que Putnam, diferentemente de Kuhn, não reconhece que esquemas conceituais distintos são incomensuráveis e descrevem conjuntos diferentes de mundos possíveis. Putnam enfatizou que sua concepção de relatividade conceitual não engendra relativismo cognitivo. Como entender essa colocação e que diferenças existem entre ambos?

\subsection{O papel}

A relatividade conceitual, para Putnam, cumpre dupla função: serve de crítica ao realismo metafísico e acomoda situações em que sistemas distintos de conceitos dão conta dos mesmos problemas.

Desde Meaning and moral science (1978), ele ressalta a dificuldade que o realista metafísico encontra para dar conta daquilo que a relatividade conceitual procura capturar. Seu célebre exemplo pode ser apresentado, de modo breve, da seguinte maneira.

Suponhamos três enredos sobre certo universo constituído por uma única linha reta. O Enredo 1 relata que existem pontos e que a linha tem partes que são "segmentos de linha" e infinitas partes chamadas "pontos". A relação "parte de" vale tanto para pontos e segmentos de linhas como para segmentos de linhas menores e maiores. O Enredo 2 conta que não existem pontos, isto é, a linha e suas partes têm extensão. Ora, o resultado ontológico com base nesses dois cenários, em que os dois enredos se equivalem, é que a propriedade "ser um objeto" é relativa à teoria. Tomemos, agora, o Enredo 3, de acordo com o qual existem somente segmentos de linha com pontos finais racionais. Nesse caso, os segmentos de linha irracionais são 
tratados como construções lógicas. Comparando os três cenários, Putnam nota que "se aceitarmos o Enredo 3 como uma descrição equivalente de "o mundo", então a própria cardinalidade do mundo se torna relativa à teoria", uma vez que os objetos nos Enredos 1 e 2 são não-enumeráveis, enquanto no Enredo 3 eles são enumeráveis (Putnam 1978, pp.130-133).

O ponto crítico para o realista metafísico é que, se esses três enredos são equivalentes e não se pode dizer como é o mundo independente de teoria, então não cabe falar de cada enredo como uma descrição "do mundo". Esse mesmo aspecto é destacado em Reason, truth and history: a resposta ao problema acerca de quais são os objetos existentes no mundo depende da teoria adotada (1981, p.52). ${ }^{14}$

Contudo, até aqui, não fica claro se, com a tese da relatividade conceitual, Putnam também contempla esquemas conceituais rivais que estejam associados a teorias rivais de uma mesma linhagem histórica. O exemplo acima, assim como outros, apresenta esquemas conceituais que dão conta dos mesmos problemas. Mas, como se sabe, as revoluções científicas destacadas por Kuhn envolvem casos de perdas de problemas, como a mudança da teoria dos vórtices de Descartes para a mecânica celeste newtoniana (em que não mais são explicados por que os planetas giram em um mesmo sentido e são aproximadamente coplanares) e a passagem da teoria do flogisto de Prestley para a teoria do oxigênio de Lavoisier (em que se perderam as explicações sobre o fato de alguns corpos serem mais similares entre si do que outros). Será que a relatividade conceitual proposta por Putnam se aplica à dinâmica do desenvolvimento científico?

Em Renewing philosophy (1992), ele coloca que a relatividade conceitual inclui, desde suas primeiras formulações, a ideia de que "estados de coisas têm muitas descrições diferentes e corretas, e mesmo descrições equivalentes podem diferir quanto ao que elas tomam como sendo "objetos"” (Putnam 1992, p.355). Nessa formulação, é possível notar que se supõe uma relação íntima entre conteúdo e descrições, para apresentar duas outras características da tese: a primeira é certa irredutibilidade entre esquemas conceituais; a segunda é a equivalência entre as diferentes descrições. De fato, em um trabalho de paciência analítica, com o qual Putnam se põe de acordo, Jennifer Case (2001) notou dois usos de "relatividade conceitual" nos textos dele: às vezes, a expressão cobre a doutrina da estreita relação entre fato e convenção; e, às vezes, ela é usada para se referir à "equivalência cognitiva" (Putnam 2001, p.436). Contudo, Case não se posiciona acerca de se são duas formulações distintas ou se ambos os usos da expressão são capturados na formulação da tese defendida por Putnam.

À luz das críticas recebidas, Putnam procurou esclarecer o que estava defendendo. O resultado, de fato, não modificou sua concepção de relatividade conceitual, tese que foi mantida depois que abandonou o realismo interno e passou a adotar o realismo natural (Putnam 2015a, p.85). Na tentativa de apresentar o alcance 
da relatividade conceitual, analisarei seus pronunciamentos, incluindo, sobretudo, o período em que passou a defender o realismo natural. ${ }^{15}$

\subsection{O escopo}

Para identificar o domínio de aplicação da relatividade conceitual defendida por Putnam, vale destacar seus exemplos recorrentes. São casos de definições de objetos geométricos, que envolvem a escolha entre incluir definição de pontos como objetos individuais ou considerá-los como sequências convergentes de esferas (Putnam 2001, p.432); casos de contagem de objetos, que compreendem a escolha entre incluir ou não somas mereológicas para responder a uma questão ontológica (Putnam 2012, p.57); exemplos da eletrodinâmica clássica, em que se tem de escolher entre tomar a ação entre partículas carregadas como mediadas por "campos" ou por "potenciais retardados de ponto-fonte" (Putnam 2001, p.432); e situações da lógica-matemática, que tratam da escolha entre tomar os conjuntos como sendo funções características (funções cujos valores são 0 e 1 ) ou assumi-los como objetos primitivos e conceituar as funções como conjuntos de pares ordenados (Putnam 2001, p.432).

Jennifer Case notou que esses exemplos estão vinculados à ciência e todos receberam certa formalização. Para evitar confusão, sugeriu o uso da expressão "linguagens opcionais", em vez de "esquemas conceituais" (Case 1997).

A ideia proposta é de que a linguagem opcional ou o esquema conceitual não é a própria linguagem, mas uma parte dela. Desse modo, é possível ter diferentes linguagens opcionais (ou esquemas conceituais) dentro de uma mesma linguagem: "[a]lguém que tenha uma linguagem natural única pode ter múltiplas linguagens opcionais e, portanto, múltiplos esquemas conceituais" (Case 1997, pp.11-2).

Assim, a sugestão, com a qual Putnam concorda, é de que se deva distinguir entre partes da linguagem natural que são uma herança cultural e "partes que são genuinamente opcionais" (Putnam 2001, p.434). ${ }^{16}$

\subsection{A formulação}

As considerações de Putnam sobre a tese da relatividade conceitual, assim como no caso de Kuhn, podem ser distinguidas em duas classes: aquelas que tratam da relação entre esquema conceitual e conteúdo $\left(R C_{1}-R C_{3}\right)$ e aquelas que apresentam as diferenças entre esquemas conceituais $\left(R C_{4}-R C_{5}\right)$. Segue uma reconstrução de suas afirmações centrais.

$R C_{1}$ : Linguagens opcionais (ou esquemas conceituais) são estruturas que se distinguem de outras partes da linguagem geral a que pertencem; elas se vinculam, sobretudo, a "imagens científicas". 
$R C_{2}$ : Nem todo enunciado é relativo a linguagens opcionais (a esquemas conceituais). $R C_{3}$ : A relatividade conceitual implica uma estreita relação entre fato e convenção (Putnam 2001, p. 437).

$R C_{4}$ : A incompatibilidade entre convenções de um par de linguagens opcionais é condição necessária para a relatividade conceitual. Linguagens opcionais não implicam que seus enunciados formem um conjunto inconsistente; a incompatibilidade se deve às diferentes convenções internalizadas nessas linguagens (Putnam 2004).

$R C_{5}$ : Linguagens opcionais são cognitivamente equivalentes, isto é, preservam explicações, de tal modo que é uma opção adotar uma ou outra.

Fica claro que $R C_{1}$ e $R C_{2}$ procuram circunscrever o campo de aplicação dos esquemas conceituais que estão em pares de linguagens opcionais. ${ }^{17}$ Por $R C_{1}$, as linguagens opcionais se aplicam a partes da nossa linguagem que estão associadas a "imagens científicas". Uma vez que as linguagens opcionais são apenas partes da linguagem natural, segue $R C_{2}$, isto é, que nem todo enunciado verdadeiro pertence a uma linguagem opcional. Quanto a esse ponto, Putnam esclarece: "[j]amais fez parte de minha doutrina da relatividade conceitual que todo enunciado é um exemplo dela ..." (Putnam 2001, p.432). Esquemas conceituais não incluem todos os pensamentos e discursos. Não abarcam, por exemplo, cadeiras e mesas, de tal modo que o enunciado "Há uma mesa diante de mim" é verdadeiro ou falso independentemente de esquema conceitual. Não haveria sentido interessante em afirmar que um tal enunciado é verdadeiro relativamente a um esquema conceitual, mas há tão somente o sentido trivial segundo o qual as propriedades semânticas do enunciado "Há uma cadeira diante de mim" e de seus termos dependem da linguagem em que estão inseridas, bem como do contexto de seu uso (Putnam 2001, p.431-2). A relatividade conceitual diz mais que isso.

À luz de $R C_{1}$ e $R C_{2}, R C_{3}$ afirma que, para os enunciados a que a relatividade conceitual se aplica, aspectos convencionais relacionados à linguagem e ao uso que dela se faz estão intimamente relacionados àquilo que compreendemos como fatos.

Em Ethics without ontology (2004), Putnam expõe sua visão acerca da incompatibilidade entre linguagens opcionais. Para tanto, ele se volta para o exemplo da soma mereológica, apresentado em The many faces of realism (1987). No mundo, há apenas três indivíduos $x_{1}, x_{2}, x_{3}$. Mereologistas afirmam que, nesse mundo, há no total sete coisas (objetos ou entidades): $x_{1}, x_{2}, x_{3}, x_{1}+x_{2}, x_{1}+x_{3}, x_{2}+x_{3}, x_{1}+x_{2}+x_{3}$. Antimereologistas reconhecem somente os três indivíduos como objetos desse mundo. Consideremos que $x_{1}$ seja totalmente vermelho e que $x_{2}$ seja totalmente preto. Agora, tomemos os seguintes enunciados:

(1) existe um objeto que é parcialmente preto e parcialmente vermelho; 
(2) existe pelo menos um objeto preto e existe pelo menos um objeto vermelho.

Para o antimereologista, o enunciado (1) é falso, caso $x_{3}$ seja totalmente vermelho ou totalmente preto. Enquanto, para o mereologista, o enunciado (1) é verdadeiro. Já o enunciado (2) é verdadeiro nas duas linguagens opcionais.

O exemplo parece mostrar que enunciados de linguagens opcionais envolvem contradições. Caso consideremos todos os enunciados verdadeiros de ambas as linguagens opcionais, aparentemente haverá enunciados incompatíveis. Mas, se levarmos em conta que um enunciado $p$ e sua negação $\sim p$ pertencem, respectivamente, às linguagens opcionais $L$ e $L^{\prime}$, e que linguagens opcionais envolvem convenções incompatíveis, então aqueles enunciados não deverão ser considerados contraditórios. (Putnam 2004, p.46). Em suma, a incompatibilidade não se aplica aos enunciados, mas às convenções $\left(R C_{4}\right)$.

Cabe ressaltar que a incompatibilidade entre convenções relacionadas aos pares de linguagens opcionais é uma condição necessária para a relatividade conceitual de Putnam. Sem essa incompatibilidade, não há relatividade conceitual, mas, talvez, pluralismo conceitual. Sem clareza dessa distinção, Putnam chegou a tomar como exemplo de relatividade conceitual os seguintes modos de apresentar as descrições dos conteúdos de um quarto: "o quarto contém uma mesa e duas cadeiras"; "o quarto contém tais e tais campos e partículas" (Putnam 2012, p.65). Contudo, como ele depois passou a notar, esse não é o caso. Podemos observar que os termos usados em ambas as descrições de quarto não formam um par de linguagens opcionais. A ideia é que o mundo, considerado relativamente a um esquema conceitual, pode ser tratado em diversos níveis, configurando uma pluralidade conceitual. No caso, como afirma Putnam:

o próprio fato de que essas descrições não pertencem a "esquemas" que podem ser sistematicamente traduzidos entre si significa que eles não são "equivalentes" no sentido técnico de "relativamente interpretáveis de modo mútuo". Essa é a razão de ilustrarem o pluralismo conceitual, mas não a relatividade conceitual no mesmo sentido (Putnam 2012, p.65).

Dessa ponderação, depreende-se também que a relatividade conceitual permite certa forma de "tradução" entre os esquemas conceituais envolvidos. Cabe, então, entender a expressão "ser relativamente interpretáveis de modo mútuo", que é propriedade distintiva das linguagens opcionais (ou esquemas conceituais) que tratam dos mesmos problemas.

O requisito de que linguagens opcionais sejam correlacionadas ou "traduzíveis" tem como base o que Putnam chamou de "fenômeno da equivalência cognitiva" (2001, p.436). Ele entende que enunciados são "traduzidos" de uma linguagem opcional para outra caso sejam preservadas, dentro da linguagem opcional, as explicações de problemas que são resolvidos dentro da linguagem da qual o novo esquema é 
uma opção $\left(R C_{5}\right)$. Não basta a traduzibilidade mútua (ou interpretabilidade mútua) das sentenças de observação para que haja equivalência cognitiva: as explicações devem ser preservadas (Putnam 2015b, p.481). Contudo, "essas traduções não preservam a "ontologia"” (Putnam 2012, p.57), tendo em vista a íntima relação entre fato e convenção $\left(R C_{3}\right)$.

\subsection{Convenção sem trivialidade}

A questão acerca de se existem somas mereológicas é, para Putnam, um pseudoproblema (Putnam 2012, p.57). Ela nos remete a uma questão de convenção, que está associada à escolha entre linguagens opcionais, de tal modo que, tomando o exemplo da contagem de objetos, adotar a linguagem da teoria de conjuntos ou a linguagem mereológica é como o caso em que se tem que escolher o lado direito ou o esquerdo para dirigir um veículo numa via de mão dupla (Putnam 2004a, p.44).

Mas, mesmo assumindo que as linguagens opcionais são convenções e que "convenção" se aplica a um artifício para solucionar um problema de coordenação, ainda cabe perguntar: se todas as explicações são preservadas, dada a equivalência cognitiva das linguagens opcionais, qual é a relevância da relatividade conceitual? Adotar uma linguagem opcional em detrimento de outra envolve alguma diferença?

De fato, entendemos que a relatividade conceitual defendida por Putnam não é uma tese trivial. Como ele próprio enfatizou, existem aspectos ontológicos e semânticos importantes. Ela "fará diferença ao dizer quantos objetos existem em certo universo de discurso" (2004a, p.38). Ou seja, ela acomoda casos sobre questões ontológicas que não são tratados por um realista metafísico. À medida que marca uma divergência de posições, ela se mostra relevante. Desse modo, não se trata de uma afirmação amplamente aceita.

Nesse sentido, se Putnam está certo ao dizer que as "traduções" de uma linguagem opcional para outra não preservam a ontologia, podemos entender que essa mudança de ontologia não se deve apenas ao uso de diferentes convenções. Objetos relativos a esquemas conceituais são constitutivos do mundo de que se trata.

Outro ponto relevante é que pode haver uma diferença de significado entre pares de enunciados vinculados a linguagens opcionais antagônicas, uma vez que uma mesma expressão pode ser usada de diferentes maneiras em linguagens opcionais. ${ }^{18}$ Fica mais claro, agora, que a "tradução" entre linguagens opcionais pode alterar os significados das expressões traduzidas, em virtude de existir a possibilidade de os pares de enunciados traduzidos (vinculados a um par de linguagens que são opcionais entre si) conterem termos sintaticamente idênticos que se relacionam diferentemente com outros termos de sua respectiva linguagem opcional (Putnam 1994b, p.246).

Em síntese, o aspecto convencional das linguagens opcionais não implica trivialidade, pois, de fato, ela não é compartilhada por realistas metafísicos, contra os quais cumpre um papel crítico central. Além disso, a escolha de uma dessas linguagens tem 
como consequência uma diferença ontológica e, em certos casos, uma diferença de significado de algumas expressões utilizadas em ambas as linguagens.

\section{Dois propósitos, duas formulações}

Os posicionamentos de Kuhn e de Putnam no tocante à relatividade conceitual, embora possuam pontos em comum, são muito distintos em virtude de seus diferentes propósitos.

De fato, em ambos os casos, a ontologia não é preservada e os significados podem não ser mantidos. Além desses aspectos comuns, outro é que a incompatibilidade não é uma propriedade característica das descrições de léxicos rivais (Kuhn) ou das linguagens opcionais (Putnam). No caso da incomensurabilidade, fica evidente que, levando-se em conta tão somente os termos incomensuráveis dos léxicos envolvidos, do que se trata em um caso pode não equivaler nem ser contraditório ao que se associa ao léxico rival, pois aquilo a que cada léxico se aplica pode não ser a mesma coisa. Ademais, ainda para Kuhn, há os casos de perdas de explicação, que evidenciam a tese de que certos enunciados de um léxico não são expressos em outro rival, de tal modo que não poderiam ser incompatíveis. No caso de Putnam, as descrições de linguagens opcionais podem parecer incompatíveis, mas, de fato, como foi frisado, a incompatibilidade deve ser atribuída às convenções das linguagens opcionais.

Por outro lado, as diferenças entre as duas formulações são importantes e profundas. Para Putnam, esquemas conceituais são linguagens opcionais, que solucionam um mesmo conjunto de problemas, adotando conjuntos de convenções distintos. Desse modo, essas linguagens opcionais preservam as explicações, sendo, nesse sentido, cognitivamente equivalentes. Kuhn, por sua vez, entende que as teorias incomensuráveis não são meras convenções e a equivalência cognitiva não é uma propriedade de teorias incomensuráveis. Cabe lembrar do registro epistemológico da incomensurabilidade, tratado sobretudo em seus textos dos anos 60 e 70. Ele envolve casos de atribuição de pesos distintos a valores cognitivos numa situação de embate entre paradigmas rivais, bem como ocorrências de conjuntos de problemas diferentes associados aos paradigmas conflitantes (Doppelt 1978). Em cada uma dessas situações, a incomensurabilidade não implica equivalência cognitiva, ainda que nem todas as mudanças acarretem perdas de explicação.

Embora ambas as formulações se contraponham ao realismo metafísico, que destaca a existência do mundo independente do aparato cognitivo, constituído por uma totalidade fixa de objetos, e de uma única linguagem que o captura, existe uma diferença central, que está vinculada aos propósitos de cada uma das teses.

A importância da relatividade conceitual para Putnam consiste em acomodar situações em que a linguagem adotada foi escolhida entre convenções incompatíveis

Principia 20(2): 285-314 (2016). 
que resolvem os mesmos problemas, sendo assim cognitivamente equivalentes, tais como os citados exemplos da eletrodinâmica clássica, da lógica-matemática, da contagem de objetos e das definições de objetos geométricos.

Todavia, a tese da relatividade conceitual proposta por Putnam não se volta para a análise do desenvolvimento do conhecimento científico. O requisito de equivalência explicativa restringe o domínio de aplicação da relatividade conceitual. Em particular, ela não daria conta da mudança da teoria do flogisto para a teoria do oxigênio, ou de qualquer outro caso de perda de explicação científica. Ela também não se aplica a situações em que não existiriam perdas de problemas, caso da mudança da mecânica newtoniana para a física einsteiniana, pois, mesmo aqui, não há equivalência explicativa. Enfim, linguagens opcionais não capturam pares de esquemas conceituais que se sucedem na história das ciências empíricas.

Para Kuhn, ao contrário, a incomensurabilidade semântica, componente central da relatividade conceitual, é um modo de cuidar das diferenças entre esquemas conceituais considerados, pelo historiador da ciência, anômalos por razão do uso de um esquema conceitual inadequado para capturar o caso histórico.

Sem dúvida, à medida que Kuhn defende a existência de esquemas conceituais rivais, sua tese se confronta com o realismo metafísico. Mas a formulação de Kuhn tem em vista a dinâmica do conhecimento científico, enquanto a formulação de Putnam analisa a relatividade conceitual tomando a linguagem da teoria no registro de sua estrutura.

O tipo de equivalência cognitiva exigida na formulação da relatividade conceitual proposta por Putnam torna a escolha de linguagens opcionais uma questão de convenção. Ao contrário, para tratar da dinâmica da ciência, Kuhn não faz da escolha de teorias (ou paradigmas) uma questão de convenção.

\section{Considerações finais}

A relatividade conceitual defendida por Putnam cumpre um papel não trivial de fazer valer casos de esquemas conceituais que, muito embora sejam equivalentes quanto às explicações, não preservam a ontologia e não garantem os significados dos termos que comparecem em ambas as linguagens opcionais. Desse modo, como vimos, essa tese se contrapõe ao realismo metafísico. Mas há outro aspecto importante para Putnam, que não foi mencionado em seus últimos escritos: ela carrega essas implicações sem envolver relativismo cognitivo. Com isso, ao assumir a distinção esquema conceitual e conteúdo, ele ainda procura manter seu compromisso com o realismo, desenvolvendo uma posição que permita relacionar pensamento e realidade.

Com base na sua tese da relatividade conceitual, Putnam, com razão, afirma que linguagens opcionais são igualmente boas, no sentido de que preservam não só pro-

Principia 20(2): 285-314 (2016). 
blemas resolvidos, mas as explicações como um todo - isto é, o que explica e o que é explicado. Isso não implica que esquemas conceituais vinculados a paradigmas rivais (kuhnianos) sejam igualmente bons, porque esquemas conceituais tratados por Kuhn não estão no escopo das linguagens opcionais, com base nas quais a relatividade conceitual de Putnam se põe.

Putnam também está correto ao afirmar que sua tese da relatividade conceitual não envolve um vale tudo (1981, p.54). Em conformidade com sua perspectiva, não se pode afirmar que "todo sistema conceitual é tão bom quanto qualquer outro". Afinal, Putnam não defende que todo esquema conceitual possui uma linguagem opcional, quer dizer, ele não adere à tese de que a relatividade conceitual se aplica a todo esquema conceitual. A relatividade conceitual "[n]ão afirma que tudo o que dizemos e pensamos pertence a um "esquema conceitual" ... nem afirma que tudo que alguém poderia chamar de um "esquema conceitual" tem uma alternativa significativa" (Putnam 2001, p.431). ${ }^{19}$ Além disso, teoria do flogisto e teoria do oxigênio possuem esquemas conceituais, mas não são propriamente pares de linguagens opcionais.

Mas vale mencionar que tampouco a relatividade conceitual presente em Kuhn implica um igualitarismo epistemológico. O relativismo quanto a boas razões, presente na proposta de Kuhn, toma a incomensurabilidade epistemológica como ponto central, não a incomensurabilidade semântica. Em um período de disputa entre membros de comunidades científicas rivais, no qual se coloca em questão qual esquema conceitual adotar, as boas razões expressam os valores, padrões de explicação e problemas relevantes que, dentre outros fatores, são colocados pelo cientista em favor da adoção de um deles. Esse tipo de relativismo, engendrado nessas circunstâncias, permite juízos de superioridade epistêmica, dos quais não se segue um igualitarismo epistemológico.

Para um relativista cognitivo kuhniano, em termos epistemológicos, cientistas que pertencem a comunidades científicas rivais podem formular juízos distintos de superioridade epistêmica em favor de seus paradigmas, com base em razões cognitivas e pragmáticas, que revelam seus valores compartilhados, como precisão, consistência, abrangência, simplicidade e fecundidade, aos quais Kuhn se refere de maneira especial (Kuhn 1977, pp.321-2). Os valores privilegiados por comunidades científicas rivais podem formar conjuntos distintos, como também é possível que, sendo os mesmos, apresentem ambiguidades, podendo ser conflitantes quando considerados em conjunto, ou, mesmo que não apresentem conflito e sejam claros, é possível que difiram quanto aos pesos que lhes são atribuídos. Esses diferentes cenários, centrados em razões internas à ciência, são alguns aspectos que podem ser levantados para explicar os diferentes juízos de superioridade epistêmica sobre os esquemas conceituais em disputa.

Uma perspectiva relativista consiste basicamente na defesa de duas teses: não 
há padrões absolutos, universais ou neutros relevantes para o contexto em questão; contudo, há padrões, mas esses são relativos a referenciais. Porém, como se nota, a primeira delas é incompatível com a suposição de que existe um padrão por meio do qual se estabelece a equivalência cognitiva entre esquemas conceituais rivais, uma marca peculiar do igualitarismo.

Sendo assim, de fato, podemos dizer que a avaliação de Putnam, segundo a qual a relatividade conceitual não envolve um vale tudo epistemológico, também se estende a Kuhn. Em outras palavras, ambas as formulações da relatividade conceitual não implicam um igualitarismo epistemológico com respeito a esquemas conceituais que se sucedem na história da ciência.

Contudo, ainda que Putnam não mencione variedades legítimas de relativismo cognitivo, sua formulação da relatividade conceitual se previne dessas formas, dada a exigência de equivalência cognitiva. Sua formulação não assimila a ideia de que certos grupos de conceitos científicos são tão interdependentes que mudanças conceituais mais profundas, geradas pela aquisição de um novo léxico, chegam a estruturar de outro modo o mundo de que trata a teoria - opondo-se, assim, a Kuhn. Ainda que a escolha entre convenções incompatíveis tenha implicações ontológicas, tal escolha não interfere nos problemas resolvidos. Mais que isso, Putnam se opõe à leitura, feita por Kuhn, da história das ciências maduras. Em particular, ele rejeita a tese da incomensurabilidade.

Para Putnam, a defesa da incomensurabilidade envolve uma confusão entre "conceito" " "concepção" (Putnam 1981, p.116). De fato, segundo Kuhn, porque a concepção de água antes de 1750 era diferente da concepção que sucedeu esse período, os conceitos não poderiam ser igualados para traduzir um esquema conceitual no outro. Conforme Putnam coloca, a distinção entre "conceito" e "concepção" torna possível a tradução. Entende-se que o conceito de $a$ equivale ao conceito de $b$, quando as referências de ambos se equivalem, enquanto uma concepção de $a$ é um conjunto de crenças sobre $a$ e uma concepção de $b$ é um conjunto de crenças sobre $b$. Na prática da tradução, um termo é traduzido à medida que as referências do velho e do novo termo se equivalem. Assim, com base nessa distinção, concepções distintas não impossibilitam a tradução de termos que se equivalem quanto às suas referências.

Contrapondo-se à incomensurabilidade, Putnam defende que a tradução envolvendo linguagens de teorias de uma mesma linhagem histórica é condição necessária para a compreensão: "[...] não podemos dizer que concepções diferem e como elas diferem se não pudermos traduzir" (1981, p.117). Na prática da tradução, ele afirma que:

[q]uando traduzimos uma palavra, como, por exemplo, temperatura, igualamos a referência e, à medida que mantemos nossa tradução, o sentido da expressão traduzida com aquele do nosso próprio termo "temperatura", ao menos quando usamos nesse contexto. [...] Nesse sentido, igualamos o "con-

Principia 20(2): 285-314 (2016). 
ceito" em questão ao nosso próprio "conceito" de temperatura. Mas proceder assim é compatível com o fato de os cientistas do século dezessete, ou quaisquer outros, poderem ter tido uma concepção diferente de temperatura, ou seja, um conjunto de crenças sobre ela e sua natureza diferente do nosso, diferentes "imagens de conhecimento", e também crenças últimas diferentes sobre muitos outros assuntos (1981, p.117).

Ora, o que vale para o termo "temperatura" vale também para outros casos da história da ciência: as referências das expressões de culturas distintas podem ser igualadas à medida que se supõe que os conceitos dos termos em jogo se equivalem.

Assim, os usos do termo "água" antes e depois de 1750 possuiriam a mesma referência. Do mesmo modo, isso valeria para o termo "planta", tal como usado em nosso discurso e em textos escritos num tempo em que a concepção de planta não incluía fotossíntese (Putnam 1981, pp.118-9; 1988, p.13). Putnam também menciona os usos do termo "elétron" nas teorias de Bohr de 1900 e de 1934: o fato de que Bohr abandonou sua concepção de que o elétron girava em torno do núcleo do mesmo modo que os planetas em torno do Sol e passou a admitir que o elétron não descreve trajetória alguma não impede que se possa fazer equivaler esses conceitos à medida que se supõe a mesma referência (1978, pp.22-24; 1988, pp.12-3).

A tradução de um esquema conceitual em outro não requer, segundo Putnam, que as crenças sejam igualadas. O sucesso interpretativo não exige que as crenças sejam as mesmas, mas que elas se tornem inteligíveis a quem opera a tradução. Mas, para que isso funcione, máximas de caridade interpretativa devem ser usadas.

Contudo, entendemos que o princípio de caridade interpretativa não é suficientemente claro para tomarmos decisões em casos cruciais, como em algumas ocorrências de "flogisto", de "éter" e de "calórico". Putnam defende que esses termos não possuem referências. Mas por que o princípio de caridade não funciona no caso do flogisto? Qual é a formulação do princípio de caridade? A máxima "interprete as palavras de tal modo que maximize o número de crenças verdadeiras que o falante teria dito à luz das nossas crenças" parece não ajudar, pois se poderia pensar que os teóricos do flogisto estivessem se referindo à valência do elétron, o que não é minimamente razoável, como o próprio Putnam notou (Putnam 1988, pp.13-4). Também implica dificuldades óbvias assumir a máxima: "interprete as crenças de outrem de tal modo que suas crenças se tornem razoáveis à luz dos pronunciamentos e práticas deles”. Esta se ajusta melhor a uma concepção kuhniana, que também usa um princípio de caridade.

De fato, parece que um juízo de razoabilidade deve reger as aplicações do princípio de caridade interpretativa. No caso de Putnam, esse princípio de ordem superior está associado à sua concepção realista das teorias científicas.

A rejeição da incomensurabilidade, por parte de Putnam, não é feita sem pressupostos realistas. Sua formulação da relatividade conceitual o permite continuar com 
caminho aberto para a elaboração de uma concepção realista acerca da relação entre pensamento e realidade, sem ceder ao relativismo cognitivo. As teorias científicas maduras que se sucedem numa mesma linhagem histórica preservam a referência de seus termos. Nessa sequência histórica, não há a relatividade conceitual defendida por Putnam, pois sua tese se põe no registro da estrutura, não no âmbito da dinâmica das teorias, e, com ela, o que se nega é a ideia de uma "descrição metafisicamente privilegiada" (Putnam 1994c, p.309).

Por outro lado, Kuhn está de acordo com a possibilidade, embora ele considere difícil de ser realizada, de que duas pessoas possam compartilhar um conceito sem compartilhar crenças sobre os objetos a que o conceito se aplica (Kuhn 1991b, p.219). Mas defende, por exemplo, que a taxonomia dos céus, associada aos padrões de semelhança e de diferença sobre os objetos celestes, descreve um céu distinto do que descrevemos com os nossos padrões e taxonomia.

Para Kuhn, não se trata de mera diferença de crenças e o apelo a observadores que exibam acordo ao apontarem os referentes dos termos de ambas as taxonomias não estabelece o ponto. Para ele,

Héspero e Fósforo são o mesmo planeta, mas é apenas sob essa descrição, somente como planetas, que podem ser reconhecidos como um e o mesmo. Até que a identidade possa ser estabelecida, não há nada a ser aprendido (ou ensinado) com o apontar (Kuhn 1991b, p.220).

A ideia defendida por Kuhn é que apontar um determinado planeta ou estrela, de maneira informativa, exige prática e conhecimento de fundo.

A diferença, entre Putnam e Kuhn, na formulação da relatividade conceitual reflete seus posicionamentos com respeito à estrutura e à dinâmica da ciência. Não obstante isso, ambos entendem que se trata de uma tese que implica a inter-relação entre fato e convenção de tal modo que o mundo não é construído em virtude dos esquemas conceituais. A diferença está no segundo componente da tese, a saber, aquele que especifica as diferenças e semelhanças entre esquemas conceituais.

Quanto à relação entre esquemas conceituais, a tese de Putnam segundo a qual a relatividade conceitual implica equivalência cognitiva entre os esquemas conceituais envolvidos evidencia que sua formulação se põe no registro da estrutura das teorias científicas. Sua tese é tão pontual que Kuhn poderia admiti-la, sem que seu modelo de desenvolvimento do conhecimento científico precisasse ser alterado. Sendo assim, eles não divergiriam quanto à tese de que a equivalência cognitiva de linguagens opcionais constituídas por convenções incompatíveis (exemplificada por casos semelhantes aos modos de contar objetos) é suficiente para a relatividade conceitual. $\mathrm{O}$ ponto de desacordo é considerá-la condição necessária.

Por outro lado, Putnam jamais admitiria a formulação da relatividade conceitual própria de uma posição kuhniana. A incomensurabilidade em geral e a semântica em

Principia 20(2): 285-314 (2016). 
particular inviabilizam os realismos, interno e natural, que Putnam procurou defender.

Sendo seus escopos tão diferentes, torna-se difícil avaliar em termos comparativos essas duas formulações, bem como dirigir uma crítica e apresentar uma alternativa a essas formas de relatividade conceitual. A situação que interessa a Putnam — a saber, a equivalência do ponto de vista cognitivo ou de solução de problemas — é diferente dos casos de revolução científica que interessam a Kuhn. Para Putnam, divergências conceituais relevantes nem sempre estão acompanhadas de diferenças do ponto de vista da solução de problemas. Kuhn, por sua vez, entende que revoluções científicas (que envolvem estruturas lexicais com diferentes capacidades de resolver problemas) geralmente estão acompanhadas de profundas mudanças conceituais (ou seja, de incomensurabilidade semântica).

Mas, de fato, a posição de Kuhn gera uma consequência ontológica extremada: não se pode falar de um mesmo mundo em ocasiões em que a estrutura lexical foi alterada de maneira ampla e sistemática, por conta de rearranjos nas relações hierárquicas ou de sobreposição entre os feixes de termos em jogo. Embora haja a possibilidade de compreensão, comparação e comunicação entre defensores de esquemas conceituais rivais, a incomensurabilidade semântica acarreta a ideia pouco intuitiva de que as descrições que usam "planta", antes da descoberta da fotossíntese, não descrevem os aspectos associados às declarações nas quais o termo "planta" é usado dentro de um esquema conceitual que pressupõe essa descoberta.

Mas, ainda que críticas à incomensurabilidade semântica e suas consequências sejam sensatas, ${ }^{20}$ frisamos que a relatividade conceitual de Putnam não se apresenta como uma alternativa no mesmo campo. Assim, por outro lado, o quadro proposto por Putnam precisa responder, nos casos em que o fenômeno da relatividade conceitual não ocorre, de que modo mudanças teóricas envolveriam alterações de esquemas conceituais que podem ser traduzidos um no outro.

Em uma comparação, o que se pode dizer é que há casos científicos relevantes de relatividade conceitual, cujas divergências conceituais não podem ser entendidas como ocorrências de incomensurabilidade semântica. O caso de contagem de objetos, exemplos retirados da geometria e situações vinculadas à eletrodinâmica e à física quântica são instâncias de um tipo de relatividade conceitual que não conduz à conclusão (pouco intuitiva) de que o mundo muda quando se alteram os esquemas conceituais, além de não envolver uma forma de relativismo cognitivo. Mesmo assim, essa tese de Putnam é forte o suficiente para cumprir seu importante papel de criticar o realismo metafísico e a tese da convergência para a suposta teoria completa e verdadeira.

\section{Agradecimentos}

Agradeço ao Prof. Dr. Caetano Ernesto Plastino as críticas e sugestões.

Principia 20(2): 285-314 (2016). 


\section{Referências}

Bird, A. 2000. Thomas Kuhn. Princeton/New Jersey: Princeton University Press.

. 2008. Incommensurability naturalized. In: L. Soler, H. Sankey and P. HoyningenHuene, (eds.) Rethinking scientific change and theory comparison: stabilities, ruptures, incommensurabilities. Dordrecht: Springer, p.21-39.

Case, J. 1997. On the right idea of a conceptual scheme. The Southern Journal of Philosophy XXXV(1): 1-18.

. 2001. The heart of Putnam's pluralistic realism. Revue internationale de philosophie 218(4): 417-30.

Davidson, D. 1974. On the very idea of a conceptual scheme. In: Inquiries into truth and interpretation. Oxford: Clarendon Press, p.183-198.

Guitarrari, R. 2016. O relativismo é autorrefutante? Trans/Form/Ação 39(1): 139-158.

Hoyningen-Huene, P. 1993. Reconstructing scientific revolutions: Thomas Kuhn's philosophy of science. Chicago, Londres: Chicago University Press.

- 2008. Commentary on Bird's paper. In: L. Soler, H. Sankey and P. Hoyningen-Huene, (eds.) Rethinking scientific change and theory comparison: stabilities, ruptures, incommensurabilities. Dordrecht: Springer, p.41-6.

— 2015. Kuhn's Development Before and After Structure. In: W. J. Devlin, A. Bokulich (eds.) Kuhn's Structure of scientific revolutions - 50 years on. Boston Studies in the Philosophy and History of Science 311. NewYork/Dordrecht/London: Springer, p.185-95.

Kuhn, T. S. 1970a. The structure of scientific revolutions. 2nd ed. Chicago: Chicago University Press.

—. 1970b [2000]. Reflections on my critics. In: The road since Structure. Chicago, Londres: The University of Chicago Press, p.123-75.

—. 1974 [1977]. Second Thoughts on Paradigms. In: The essential tension. Chicago, Londres: The University of Chicago Press, p.293-319.

- 1977 Objectivity, value judgment, and theory choice. In: The essential tension. Chicago, Londres: The University of Chicago Press, p.320-339.

- 1981 [2000]. What are scientific revolutions? In: The road since Structure. Chicago, Londres: The University of Chicago Press, p.13-32.

- 1983 [2000]. Commensurability, comparability, communicability. In: The road since Structure. Chicago, Londres: The University of Chicago Press, p.33-57.

- 1989 [2000]. Possible worlds in history of science. In: The road since Structure. Chicago, Londres: The University of Chicago Press, p.58-89.

- 1990. Dubbing and redubbing: the vulnerability and rigid designation. In: C. W. Savage (ed.) Minnesota Studies in the Philosophy of Science v. XIV. Minneapolis: University of Minnesota Press, p.298-318.

- 1991a [2000]. The road since Structure. In: The road since Structure. Chicago, Londres: The University of Chicago Press, p.90-104.

- 1991b [2000]. The natural and human science. In: The road since Structure. Chicago, Londres: The University of Chicago Press, p.208-23.

- 1992 [2000]. The trouble with the historical philosophy of science. In: The road since Structure. Chicago, Londres: The University of Chicago Press, p.105-20. 
1993 [2000]. Aferwords. In: The road since Structure. Chicago, Londres: The University of Chicago Press, p.224-52.

Putnam, H. 1975 [1979]. The meaning of "meaning". In: Mind, language and reality. Philosophical papers vol. 2. Cambridge: Cambridge University Press, p.215-71.

. 1978. Meaning and the moral science. Boston/London/Henley: Routledge \& Kegan Paul.

— 1981. Reason, truth and history. Cambridge: Cambridge University Press.

- 1987. The many faces of realism. LaSalle, Illinois: Open Court.

- 1988. Representation and reality. Cambridge: MIT Press.

- 1990. Realism with a human face. Massachusetts: Harvard University Press.

- 1992. Renewing philosophy. Cambridge: Harvard University Press.

—. 1994a. The Dewey Lectures 1994 - Sense, nonsense, and the senses: an inquiry into the powers of the human mind. The Journal of Philosophy 91.

- 1994b. Comments and replies. In: P. Clark, B. Hale (ed.) Reading Putnam. Oxford: Blackwell, p.242-95.

_ 1994c. The question of realism. In: H. Putnam, J. Conant (ed.) Words and life. Cambridge: Harvard University Press, p.295-312.

- 2001. Reply to Jennifer Case. Revue internationale de philosophie 218(4): 431-8.

- 2004a. Ethics without ontology. Cambridge, Mass.: Harvard University Press.

- 2004b. Sosa on internal realism and conceptual relativity In: J. Greco (ed.) Ernest Sosa: And His Critics. Oxford: Blackwell, p.233-248.

- 2012. From quantum mechanics to ethics and back again. In: Philosophy in an age of science: physics, mathematics, and skepticism. Cambridge: Harvard University Press, p.5171.

- 2015a. Intellectual autobiography of H. Putnam. In: R. E. Auxier, D. R. Anderson, L. E. Hahn (eds.) The Philosophy of Hilary Putnam. Chicago: Open Court, p.3-110.

. 2015b. Reply to Yemima Ben-Menahem. In: R. E. Auxier, D. R. Anderson, L. E. Hahn (eds.) The Philosophy of Hilary Putnam. Chicago: Open Court, p.481-5.

Sosa, E. 1993. Putnam's Pragmatic Realism. The Journal of Philosophy 90(12): 605-26.

ROBINSON GUITARRARI Departamento de Filosofia/UFRRJ robinson.guitarrari@gmail.com

\section{Notas}

${ }^{1}$ No período em que defendeu o realismo interno, Putnam chamou essa posição de realismo metafísico. Foi uma fase em que defendeu um tipo de semântica verificacionista. Depois, ele assumiu uma posição metafísica ao defender o realismo natural (também chamado de senso comum), contrapondo-se a todas as formas de verificacionismo (Putnam 2012, pp.62-63). Por conta disso, ele diferencia seu realismo natural daquele metafísico, criticado desde sua defesa do realismo interno, referindo-se a ele como um realismo metafísico com letras maiúsculas ou um realismo metafísico não humano. Basicamente, esse realismo não humano defende três teses: (1) o mundo externo é uma totalidade fixa de objetos (observáveis e inobserváveis)

Principia 20(2): 285-314 (2016). 
e suas propriedades, cuja existência é independente de qualquer propriedade cognitiva que dele se possa ter; (2) existe uma única linguagem correta e completa que captura o mundo; e (3) a verdade é uma correspondência entre linguagem e mundo. Tal posição, segundo Putnam, assume o ponto de vista do olho de Deus (Putnam 1981, p.49). Nesse artigo, a expressão "realismo metafísico" substitui "realismo metafísico não humano".

${ }^{2}$ Putnam possui formulações aparentemente equivalentes, que, separadas do contexto, mostram-se obscuras. Ele afirmou: "[o]bjetos não existem independentemente de esquemas conceituais" (Putnam 1981, p.52). A ambiguidade dessa formulação está em não se saber se o mundo existe em virtude do esquema conceitual ou não. Ao lado de pronunciamentos como "[...] a mente e o mundo constituem conjuntamente a mente e o mundo" (Putnam 1981, p.xi) é possível se enganar a respeito da sua posição. Porém, à luz das críticas recebidas, ele procurou especificar o que tencionava defender com a tese da relatividade conceitual (Putnam 2004a). Nesse aspecto, é relevante notar que Boyd manteve, no recente artigo supracitado, o aspecto ambíguo das primeiras formulações de Putnam.

${ }^{3}$ Sobre as declarações de Putnam acerca de suas mudanças de posicionamento quanto ao realismo, confira "Sosa on internal realism and conceptual relativity" (Putnam 2004b, p.233, n. 2) e seu artigo "From quantum mechanics to ethics and back again" (Putnam 2012).

${ }^{4} \mathrm{O}$ exame proposto não se insere no contexto em que se questiona a dicotomia esquema conceitual/conteúdo, considerada o terceiro dogma do empirismo por Davidson, em seu célebre artigo "On the very idea of a conceptual scheme" (1974). Nesse sentido, no presente artigo, não tomaremos posição em relação à tese de Davidson segundo a qual tal dicotomia não pode ser estabelecida e a própria ideia de esquema conceitual deve ser rejeitada, mas simplesmente procuraremos destacar o entendimento de Putnam e de Kuhn sobre a relatividade conceitual e suas implicações.

${ }^{5}$ Davidson faz essa associação, ao criticar a compreensão filosófica de Kuhn sobre o desenvolvimento da ciência.

${ }^{6}$ Kuhn prefere a noção de "esquema conceitual" à de "taxonomia lexical", embora use as duas expressões. Nas palavras de Kuhn: "o que eu chamei de taxonomia lexical poderia ser mais bem denominado um esquema conceitual" (1991a, p.94). A ideia é que um esquema conceitual é um "módulo mental" que permite conceber e delimitar um conjunto de crenças. No presente artigo, serão utilizadas as duas expressões para expor a posição kuhniana.

${ }^{7}$ Em 1994, o livro inacabado de Kuhn intitulava-se The plurality of worlds: an evolutionary theory of scientific development (Hoyningen-Huene 2015).

${ }^{8}$ Hoyningen-Huene tem clareza sobre limitações de uma aproximação entre Kuhn e Kant. Segundo ele, "o tratamento de Kuhn não é realmente kantiano", considerando que Kuhn toma os aspectos das coisas, o espaço, o tempo e a causalidade como simplesmente dados ao sujeito epistêmico antes que tal sujeito estabeleça relações de similaridade e dissimilaridade, o que não é próprio de uma posição kantiana; além disso, Kuhn não trata propriamente da coisidade, um tema central do ponto de vista kantiano (Hoyningen-Huene 2008, p.44 n.2).

${ }^{9}$ Neste caso, a tese é assim apresentada: “[s]e duas teorias são incomensuráveis, elas devem ser afirmadas em linguagens mutuamente intraduzíveis" (Kuhn 1983, p.34).

${ }^{10}$ Sobre esse ponto, Kuhn afirma: "[e]stender a quantificação para incluir mundos acessíveis somente por recurso a outras linguagens parece, no melhor dos casos, inútil e, em algumas aplicações, pode ser uma fonte de erro e confusão. [...] Pelo menos em sua aplicação ao desenvolvimento histórico, o poder e a utilidade dos argumentos de mundos-possíveis pa-

Principia 20(2): 285-314 (2016). 
recem exigir restrição destes aos mundos acessíveis por um léxico determinado, os mundos que podem ser estipulados pelos membros de uma dada comunidade ou cultura linguística" (Kuhn 1989, pp.64-5).

${ }^{11}$ Nesse quadro realista metafísico, essa teoria causal da referência se ajusta a uma concepção de verdade como correspondência entre linguagem e mundo.

12 Putnam tem defendido a relatividade conceitual desde Meaning and moral science (1978). A expressão "relatividade conceitual" veio com The many faces of realism (1987) e com artigos de Realism with a human face (1989, pp.30-42). Antes, Putnam usou a expressão "relativismo conceitual" (Putnam 1992, p.356).

${ }^{13}$ A "semântica verificacionista", tese central do realismo interno de Putnam, concebe a verdade como aquilo que é verificável em condições epistemicamente ideais (o que é racionalmente aceitável sob condições ideais). A verdade assim concebida é estável e convergente, diferentemente da justificação aqui e agora. Mas, ainda que distinta do que é racionalmente aceitável, ela não é independente de todo tipo de justificação. Isso mostra sua natureza epistêmica e transcultural, ficando assim entre uma noção correspondencial, característica do realismo metafísico, e uma concepção relativista de verdade e de racionalidade. Putnam afirma que "concedeu, por várias razões, que podemos ser incapazes de obter condições epistemicamente ideais com respeito a algumas de nossas investigações; por isso, de acordo com esta teoria, a verdade pode exceder o que podemos verificar como uma questão de fato" (Putnam 2015, p.83).

${ }^{14}$ Putnam escreveu: ““[o]bjetos” não existem independentemente de esquemas conceituais. Recortamos o mundo em objetos quando introduzimos um ou outro esquema de descrição" (1981, p.52).

${ }^{15}$ Putnam indica que não houve alteração na tese da relatividade conceitual (cf. Putnam 2015a, pp.85-6), o que autoriza o uso de seus textos referentes ao período em que defendeu o realismo natural.

${ }^{16}$ Putnam considera os esquemas conceituais em um registro científico. Ele circunscreve as "linguagens opcionais" como parte do domínio da linguagem em geral. Não é o caso de que seus esquemas conceituais se apliquem a ela indistintamente. Ao contrário, ele distingue, dentro da linguagem natural, as partes que são "heranças culturais" daquelas que são "linguagens opcionais" (os esquemas conceituais), e, subscrevendo os esclarecimentos de Case, Putnam entende que essas linguagens opcionais são linguagens científicas que receberam certa formalização.

${ }^{17}$ Notemos que podem existir pares de esquemas conceituais que não correspondem a pares de linguagens opcionais, como, por exemplo, teorias científicas de uma mesma linhagem histórica que se sucedem no tempo e que respondem a diferentes conjuntos de problemas.

18 Para Putnam, o significado de uma expressão está relacionado ao modo como ela é usada. Assim, ele se opõe à exigência de apresentação de um sinônimo ou paráfrase, como requer uma noção de significado comumente vinculada à concepção de Davidson (Putnam 2004a, pp.40-1).

${ }^{19}$ Fica claro que Putnam distingue o fenômeno da relatividade conceitual, que envolve linguagens opcionais (dadas as formulações da relação entre esquema conceitual/conteúdo e das diferenças entre esquemas conceituais opcionais), daquelas ocorrências de esquemas conceituais que não possuem uma alternativa cognitivamente equivalente. "Esquemas conceituais" tem escopo amplo, englobando casos de relatividade conceitual e casos sem relatividade

Principia 20(2): 285-314 (2016). 
conceitual. Para evitar esse tipo de ambiguidade, vale usarmos, para os casos de relatividade conceitual, a expressão "linguagens opcionais", em vez de "esquemas conceituais", tal como sugeriu Case.

${ }^{20}$ Em "O relativismo cognitivo é autorrefutante?", procuramos responder à acusação de autorrefutação, elaborada por Putnam contra o relativismo kuhniano associado à incomensurabilidade semântica (Guitarrari 2016).

Principia 20(2): 285-314 (2016). 